\title{
INTERAÇÃO NO CIBERESPAÇO E FORMAÇÃO DE PROFESSORES: ANÁLISE DA SALA DE INTERAÇÃO VIRTUAL DO PROGRAMA ESCOLA DE GESTORES NA UNIVERSIDADE FEDERAL DE OURO PRETO
}

\author{
INTERACCIÓN EN EL CIBERESPAÇO Y FORMACIÓN DE PROFESORES: \\ ANÁLISIS DE LA SALA DE INTERACCIÓN VIRTUAL DEL PROGRAMA \\ ESCOLA DE GESTORES EN LA UNIVERSIDAD FEDERAL DE OURO PRETO
}

\section{INTERACTION IN CYBERSPACE AND TEACHER TRAINING: ANALYSIS OF THE VIRTUAL INTERACTION ROOM OF THE PROGRAMA ESCOLA DE GESTORES AT THE FEDERAL UNIVERSITY OF OURO PRETO}

\author{
Breynner R. OLIVEIRA ${ }^{1}$ \\ Lídia G. MARTINS ${ }^{2}$ \\ Adriana Otoni S. DUARTE ${ }^{3}$
}

RESUMO: Este artigo analisa a contribuição da Sala de Interação Virtual para o processo de mediação e supervisão do trabalho pedagógico no Programa Nacional Escola de Gestores (PNEG), na Universidade Federal de Ouro Preto (UFOP). É um dos resultados de uma pesquisa realizada com a equipe de formação do programa, cujo objetivo foi avaliar como os saberes docentes da equipe de formadores são mobilizados e se contribuem para a conformação de um saber polidocente; foram entrevistados 26 profissionais da equipe polidocente que atuaram no programa no período de 2013 a 2015. A análise de conteúdo foi assistida pelo software NVivo®. Os resultados indicam que a Sala de Interação Virtual é um espaço que promove rodadas de interações e trocas com outras pessoas da equipe, contribuindo para a implementação das ações de formação no ciberespaço.

PALAVRAS-CHAVE: Educação a distância (EaD). Formação continuada de professores. Saber polidocente. Interação.

RESUMEN: Este artículo analiza la contribución de la Sala de Interacción Virtual para el proceso de mediación y supervisión del trabajo pedagógico en el Programa Nacional Escola de Gestores (PNEG), en la Universidad Federal de Ouro Preto (UFOP). Uno de los resultados de una investigacíon realizada con el equipo de formación del programa, cuyo objetivo fue evaluar cómo los conocimientos docentes del equipo de formadores son movilizados y se contribuyen a la conformación de un saber polidocente, fueron entrevistados 26 profesionales del equipo polidocente que actuaron en el PNEG, de 2013 a 2015. El análisis de contenido fue asistido por el

${ }^{1}$ Doutor em Educação. Professor-adjunto da Universidade Federal de Ouro Preto e do Programa de Pósgraduação em Educação. Membro do Núcleo de Avaliação Educacional (NAVE). breynner@cead.ufop.br ${ }^{2}$ Técnica em Assuntos Educacionais da Universidade Federal de São Paulo (UNIFESP). lidia.martins30@gmail.com

${ }^{3}$ Doutoranda em Educação. Professora da Universidade do Estado de Minas Gerais. adrianasantunesduarte@gmail.com 
software NVivo®. Los resultados indican que la Sala de Interacción promueve sucesivas rondas de intercambios entre el equipo, contribuyendo a la implementación de las acciones de formación en el ciberespacio.

PALAVRAS CLAVE: Educación a distancia (EaD). Formación continuada de profesores. Saber polidocente. Interacción

ABSTRACT: This paper analyzes the Virtual Interaction Room to the mediation process and pedagogical supervision in the Programa Escola de Gestores (PNEG) at the Federal University of Ouro Preto (UFOP). It is one of the results of a research carried out with the program's team, whose objective was to evaluate how their teaching knowledge is mobilized. 26 professionals that worked in the program from 2013 to 2015 were interviewed. Content analysis was assisted by NVivo®, a software used in qualitative research. The results indicate that the Virtual Interaction Room is a space that promotes successive rounds of interactions with other team members, contributing to the implementation of actions in cyberspace.

KEYWORDS: On line education. Teacher training. Politeaching knowledge. Interaction

\section{Introdução}

Pretende-se, neste artigo, descrever e analisar a contribuição da Sala de Interação Virtual para o processo de mediação e supervisão do trabalho pedagógico no Programa Nacional Escola de Gestores (PNEG), na Universidade Federal de Ouro Preto (UFOP). O PNEG é uma das ações que integram a política nacional de formação continuada de professores, coordenada pelo Ministério da Educação brasileiro através da Secretaria de Educação Básica (MEC/SEB), ofertado na modalidade a distância.

A discussão aqui empreendida surge de uma das dimensões analíticas que resultaram de uma pesquisa ${ }^{4}$ realizada com a equipe de formação do programa, cujo objetivo foi avaliar como os saberes docentes da equipe de formadores são mobilizados, e se contribuem para a conformação de um saber polidocente. Para tanto, foram realizadas entrevistas individuais em profundidade com profissionais que compuseram a equipe polidocente que atuou no PNEG no período de 2013 a 2015. A análise de conteúdo das entrevistas foi assistida pelo software $\mathrm{NVivo}{ }^{\circledR}$, que possibilitou a leitura e a classificação das fontes utilizadas, a partir do plano prévio de categorias analíticas.

${ }^{4} \mathrm{~A}$ pesquisa "Interação da equipe polidocente de formação na EaD: a experiência da especialização em Gestão Escolar da Universidade Federal de Ouro Preto (UFOP)" foi desenvolvida no âmbito do Programa de Bolsas de Iniciação Científica e Tecnológica Institucional da FAPEMIG (PROBIC-FAPEMIG/UFOP) e do Programa Institucional de Voluntários de Iniciação Científica (PIVIC/UFOP). 
O artigo está estruturado em três partes, além da introdução, aspectos metodológicos e considerações finais. A primeira parte apresenta uma breve discussão sobre a educação a distância on line $(\mathrm{EaD})$ e sua relação com a sociedade em rede, no contexto das tecnologias. A segunda trata das possibilidades da $\mathrm{EaD}$ para a formação continuada de professores no Brasil. Na terceira seção, apresenta-se o desenho formativo e a equipe polidocente do programa na UFOP. Na quarta parte, a Sala de Interação Virtual é analisada a partir das entrevistas realizadas, com foco nas percepções, saberes mobilizados e no apoio institucional.

\section{A sociedade em rede e a educação a distância on line (EaD)}

Castells (2000) é contundente quando afirmou que um novo mundo estava tomando forma no inicio do século XXI. Para o autor, esse novo paradigma estrutural, a "sociedade em rede", é resultado de três grandes processos independentes que convergem entre si, coincidentemente: (1) a reestruturação dos sistemas produtivos e dos modelos econômicos, no escopo da globalização dos mercados e da dinâmica estatal; (2) avanços consideráveis no campo da tecnologia da informação, proporcionando ferramentas para a formação de redes e virtualização da comunicação e da informação em nível mundial e (3) articulação entre diversos e complexos movimentos socioculturais pós 1960 que têm redesenhado as relações estabelecidas entre os indivíduos, as instituições, as organizações e os vários grupos que dão consistência ao chamado "tecido social".

A sociedade em rede é, portanto, a marca de um tempo caracterizado por um conjunto de transformações econômicas, políticas, sociais e culturais potencializadas ou permeadas por sucessivos avanços tecnológicos, através das redes digitais. Nesta nova sociedade, a inovação e a criação emergem como movimentos dialéticos importantes, contribuindo decisivamente para que novas tecnologias sejam produzidas e disseminadas. A emergência de (novos) dispositivos de comunicação e interação (celulares, computadores pessoais, tablets, apps, softwares, smartphones, notebooks, dentre outros) dão materialidade a esse processo, modificando radicalmente o acesso à informação e a produção do conhecimento. É nesse sentido que Kensky (2007) afirma que há, então, uma intensa e profunda redefinição dos processos de produção e 
circulação de bens e serviços e da dinâmica que envolve a interação entre os indivíduos, grupos, organizações e instituições, tanto públicas quanto privadas, em nível global.

Nessa mesma direção, a flexibilização dos tempos, a relativização das distâncias, a adoção de novas formas de socialização e padrões de comportamento definem múltiplas combinações, provocando, segundo Lévy (2009), uma verdadeira revolução nas relações sociais quando outra dimensão de espaço passa a fazer parte do cotidiano das interações - o ciberespaço. Para Lévy (1999), o ciberespaço é a dimensão que agencia, articula, conecta, processa, potencializa e relativiza a pluralidade de ideias, processos e saberes que transitam a partir dos dispositivos digitais e em rede.

Castells (2000), ao analisar essa dinâmica na sociedade em rede e no ciberespaço, entende que a interação social on line desempenha um papel cada vez mais importante na organização social, integrando os tempos real e virtual, além de promover a formação de comunidades virtuais. De acordo com Silva (2012), a navegação pelo ciberespaço não se limita à obtenção de dados, mas ao estabelecimento de uma rede de trocas de informações, compromissos, ofertas, promessas, aceitações, recusas, reclamações e apoios, atos de comunicação onde o mundo privado da experiência pessoal e privada é diluído no mundo interpessoal e grupal das interações que ali se materializam.

Essa análise é bastante convergente com o conceito de liquidez proposto por Bauman (2001). Ao comparar o estado da sociedade moderna com a dinâmica dos líquidos, incapazes de manter a forma ao assumirem contornos mutáveis e fluidos, o autor afirma que tanto o tempo quanto o espaço - o tempo e o espaço da sociedade em rede - são provisórios e inacabados. A velocidade imposta pela tecnologia e pelas interações proporcionadas pelo mundo digital impõe a noção permanente de que tudo é temporário e está em transformação.

É nesse contexto que o conceito de cibercultura se manifesta, designando o conjunto das técnicas materiais e intelectuais, das práticas, atitudes, maneiras de pensar e os valores que se desenvolvem conjuntamente com o crescimento do ciberespaço (LÉVY, 1999). A cibercultura está, portanto, imersa e diluída na liquidez das relações econômicas, políticas, sociais, culturais e humanas que conectam simultaneamente os indivíduos, os grupos e as instituições, permitindo que a criação, a partilha e a transmissão de conhecimento aconteçam, potencializando novas formas de aprendizagem, relacionamento e comportamento. 
Para o campo da educação e para as organizações escolares, esse novo paradigma abre um enorme leque de possibilidades, uma vez que a economia em rede inaugura um novo espaço de interação que prescinde das fronteiras geográficas formais, além dos muros, dos tempos e da presencialidade. Nesse sentido, a disseminação do conhecimento emerge com um dos fatores estratégicos nesse processo, concretizado através dos diversos recursos tecnológicos disponíveis - as Tecnologias Digitais da Informação e da Comunicação (TDICs). Ao serem incorporadas pela escola, pelos professores, pais e alunos, as TDICs inauguram, aceleram e/ou aprofundam o fenômeno da midiatização $n a / d a$ aprendizagem. É nesse contexto que a educação a distância on line emerge (EaD).

A EaD é uma modalidade que relativiza o tempo, o espaço e as distâncias, de modo que os sujeitos possam ensinar e aprender virtualmente, síncrona ou assincronamente, mediados pelas TDICs. Através de uma relação virtual amparada por um leque de recursos tecnológicos, os atores envolvidos podem criar vínculos e estratégias de interação que proporcionarão relacionamento tanto no ciberespaço quanto no espaço real, permitindo a troca e a sistematização de saberes.

Tais características são uma oportunidade estratégica para a formação inicial e continuada. Por causa de suas potencialidades, a EaD tem ocupado, ao longo das últimas décadas, importante lugar no processo de qualificação profissional não apenas no Brasil, mas em todo o mundo. Nos últimos anos, o governo brasileiro tem dado especial atenção a essa modalidade, sobretudo no que diz respeito à formulação de políticas públicas voltadas para a expansão e democratização do acesso ao ensino superior.

Do ponto de vista conjuntural, o contexto que justifica a emergência da educação a distância tem profundas relações com o ambiente econômico e com a disseminação das TDICs, sobretudo no que se refere à crescente necessidade de expansão do ensino e qualificação profissional nos países desenvolvidos e em desenvolvimento, associado a um processo de ampliação do acesso à educação formal, em especial a educação superior. Em tempos em que a sociedade também se articula em redes no ciberspaço, a flexibilidade é um dos principais ativos dessa modalidade, o que permite aos estudantes, professores e às instituições conjugarem distintas estratégias de formação, constituindo espaços virtuais em que a sala de aula está em todo lugar, a qualquer momento.

Em relação às instituições que aderiram a essa modalidade, em que pesem os diversos e distintos modelos de oferta, um conjunto de processos, recursos e pessoas 
deve estar formalmente vinculado a fim de dar condições para que essa dinâmica se materialize e seja operacionalizável. São utilizadas tecnologias, ferramentas, programas computacionais, livros e recursos da internet que devem estar disponíveis em um ambiente virtual de aprendizagem (AVA). A interlocução é possível por conta de suportes tecnológicos, utilizados tanto para a comunicação síncrona (web conferências, salas de bate-papo, dentre outras) quanto para comunicação assíncrona (fóruns, ferramentas de edição de textos, envio de atividades avaliativas, e-mails, etc.).

Consequentemente, os processos formativos e pedagógicos ganham novos contornos e, segundo Belloni (2012), o papel do professor é profundamente modificado, especialmente se a educação presencial for tomada como referência. $\mathrm{Na} \mathrm{EaD}$, o docente passa a desempenhar múltiplas funções, interagindo com outros profissionais que também estão envolvidos na formação: supervisores, professores-conteudistas, tutores, designers, jornalistas, roteiristas, cinegrafistas, profissionais da computação e da área de tecnologia são alguns dos atores que passam a atuar nessa modalidade.

Em função de sua dinâmica e da virtualidade do tempo e do espaço, a preparação de uma aula, curso, conteúdo ou ambiente requer a incorporação de uma diversidade de recursos e mídias, vinculando todos aqueles sujeitos, de modo fragmentado e segmentado. Várias pessoas desempenham tarefas direta ou indiretamente ligadas ao ensino, respaldadas pela dimensão institucional que deverá ser a responsável por sistematizar, articular e gerenciar tais ações a fim de assegurar que o trabalho seja realizado de forma coletiva e cooperativa. Se o professor não trabalha mais sozinho e tem seu papel redimensionado em função das especificidades do trabalho pedagógico, deixa de ser, segundo Belloni (2012), uma entidade individual, transformando-se em uma entidade coletiva.

Como ultrapassar a dimensão institucional definida por Belloni, dando visibilidade aos sujeitos que desempenham tais papéis? Mill (2010) avança nesta direção quando se propõe a investigar quem é o docente na EaD. Para este autor, esse trabalho, ao contrário do que se dá em uma sala de aula presencial, não é realizado por uma única pessoa, que se encarrega de todo o processo de formação, mas por um polidocente, isto é, uma equipe diversificada de educadores e assessores que, juntos, porém não na mesma proporção, mobilizam os saberes de um professor: os conhecimentos específicos da disciplina; os saberes didático-pedagógicos do exercício docente, tanto para organizar os conhecimentos da disciplina nos materiais didáticos quanto para acompanhar os estudantes; e os saberes técnicos, para manuseio dos 
artefatos e tecnologias processuais, para promover a aprendizagem de conhecimentos dos estudantes.

\section{A EaD: estratégia para a formação continuada de professores em tempos líquidos}

No que se refere às políticas educacionais, uma nova agenda se impõe ao Estado, resultado dos processos sócio-político-econômicos que têm marcado os diversos governos nacionais, impulsionada pela sociedade em rede. Para o caso brasileiro, a capacidade responsiva do Estado no campo educacional tem passado por alterações que são o reflexo da liquidez desse tempo, em constante transformação.

No Brasil, a "janela de oportunidades" para a EaD se deu com a Lei de Diretrizes e Bases da Educação Nacional - LDBEN/1996 -, que prevê tal modalidade como alternativa para a formação inicial e continuada. O número de alunos matriculados, cursos oferecidos e instituições credenciadas que aderiram a essa modalidade tem crescido consideravelmente desde o início dos anos 2000.

Caracterizado por um amplo território nacional, com grande diversidade cultural e especificidades regionais, as demandas por formação de professores no país exigem do governo federal estratégias em larga escala. É nesse contexto que a modalidade a distância on line mostra-se eficiente porque consegue alcançar uma gama muito grande de sujeitos dispersos geograficamente através da conexão à internet, criando um espaço de formação e uma rede de trocas entre os cursistas, mediados por um ambiente virtual de aprendizagem (AVA) e por docentes facilitadores, exigindo novas posturas de todos os envolvidos no processo educacional (MORAN, 2007).

Segundo Gatti (2008), desde 2003 o MEC tem se articulando com estados, municípios e universidades públicas a fim de criar uma rede que seja capaz de promover sinergia entre as várias políticas de formação continuada de professores financiadas pelo governo federal. Na medida em que há uma clara aproximação entre os atores institucionais envolvidos, um novo ethos para a formação de professores aparece, mais permeável a essa nova conjuntura.

No nível local, cada universidade tem definido suas estratégias de atuação a fim de atender às demandas dessa rede. Se, por um lado, tais instituições precisam mobilizar seus saberes acadêmicos para interagirem com os professores-alvo das políticas, por outro é preciso que tais saberes sejam capazes de dialogar com as exigências que o ciberespaço impõe, já que a grande maioria das ações de formação continuada acontece 
exclusiva ou parcialmente on line. A conformação do desenho pedagógico, propostas curriculares e estratégias didático-pedagógicas tornam-se cruciais para que a implementação seja exitosa. Claro está, portanto, que a gestão de uma equipe polidocente é uma questão central para o processo de formação.

A partir do itinerário percorrido nestas duas seções, a seguinte tratará de descrever e analisar as estratégias de coordenação e promoção da interação no ciberespaço da equipe polidocente no âmbito do PNEG na UFOP.

\section{O PNEG na UFOP: desenho e estratégias para a formação de professores}

A formação continuada de professores é um dos pilares da política nacional de fortalecimento e promoção da qualidade da escola pública. Articulada com um conjunto de ações financiadas pelo MEC e implementadas em parcerias com os estados, municípios e instituições de ensino, a disseminação de programas dessa natureza pretende, segundo Gatti (2008), oferecer oportunidades de (in)formação, reflexão, discussão e trocas que favoreçam o aprimoramento profissional, em qualquer de seus ângulos, em qualquer situação.

Uma dessas ações é o PNEG, componente do compromisso "Todos pela Educação", que é um plano de metas que integra o Plano de Desenvolvimento da Educação (PDE) e diz respeito à mobilização em torno da melhoria da educação básica no Brasil. O público-alvo do programa são os profissionais que integram a equipe gestora de escolas públicas, sendo priorizados aqueles municípios com Índice de Desenvolvimento da Educação (IDEB) abaixo da média nacional.

O PNEG começa a ser gradualmente implementado em nível nacional a partir de 2004, com o objetivo de formar gestores escolares para atuarem em escolas públicas. Para tanto, o PNEG oferece dois cursos de especialização na modalidade a distância, sendo um voltado para a formação de gestores escolares, com carga horária de 400 horas e outro para a formação de coordenadores pedagógicos, com carga horária de 405 horas.

Para contemplar as várias regiões do país, o Governo Federal firmou convênios com várias Universidades Federais e Estaduais para que pudessem operacionalizar o processo de formação desses gestores. A UFOP passou a integrar esse grupo em 2011, com o objetivo de formar, em nível de pós-graduação lato sensu, especialistas em Gestão Escolar para atuar nas escolas públicas de Educação Básica do Estado de Minas 
Gerais, visando à ampliação de suas capacidades de análise e resolução dos conflitos e desafios que podem emergir no cotidiano desses espaços. Entre 2012 e 2017, foram formadas quatro turmas, distribuídas em 10 polos de apoio presencial, cobrindo quase 170 municípios no estado. Aproximadamente 1200 gestores foram certificados nesse período.

A proposta pedagógica do curso de Gestão Escolar assenta-se na relação teoriaprática, que expressa uma concepção de formação humana e de gestão educacional dentro dos marcos da democracia e da cidadania, buscando incentivar inovações na prática cotidiana da gestão escolar que concorram para a elevação qualitativa do padrão de escolaridade da educação básica (OLIVEIRA, 2012). Para possibilitar esse processo de formação, o currículo do curso é estruturado em torno de três eixos articulados: (1) o direito à educação e à função social da educação básica; (2) políticas de educação e a gestão democrática da escola e (3) projeto político-pedagógico e práticas democráticas na gestão escolar. Esses eixos estão organizados em oito salas ambientes ${ }^{5}$ e as ementas, conteúdos programáticos, propostas de atividades e demais conteúdos de cada sala são disponibilizadas pelo MEC através do ambiente virtual de aprendizagem Moodle ${ }^{6}$.

Na UFOP, a equipe de formação assumiu a seguinte configuração: coordenação geral e vice, responsáveis pela gestão institucional do(s) curso(s); professores coordenadores de sala-ambiente, dedicados à seleção e preparação dos conteúdos de cada disciplina; supervisão geral e supervisão pedagógica, responsáveis pela articulação do trabalho pedagógico; professores de turma e assistentes de turma, que realizam a gestão acadêmica e a mediação dos conteúdos; suporte administrativo, que se dedica às atividades de secretaria e suporte tecnológico, responsável pela gestão do AVA. A Figura 1 apresenta esse desenho, com a noção dos fluxos.

Figura 1 - Equipe do Programa Escola de Gestores na UFOP.

${ }^{5}$ As salas ambientes são: Introdução ao Ambiente Virtual Moodle (40h); Fundamentos do Direito à Educação (60h); Políticas e Gestão na Educação (60h); Planejamento e Práticas da Gestão Escolar (60h); Tópicos Especiais: Conselhos Escolares (30h); Oficinas Tecnológicas (30h); Projeto Vivencial (80h); Trabalho de Conclusão de Curso (40h).

${ }^{6}$ Moodle - Modular Object-Oriented Dynamic Learning Environment -, é um software livre embasado na Pedagogia Construcionista que permite a criação, gerenciamento e oferta de cursos através da criação de Ambientes Virtuais de Aprendizagem (AVA). 


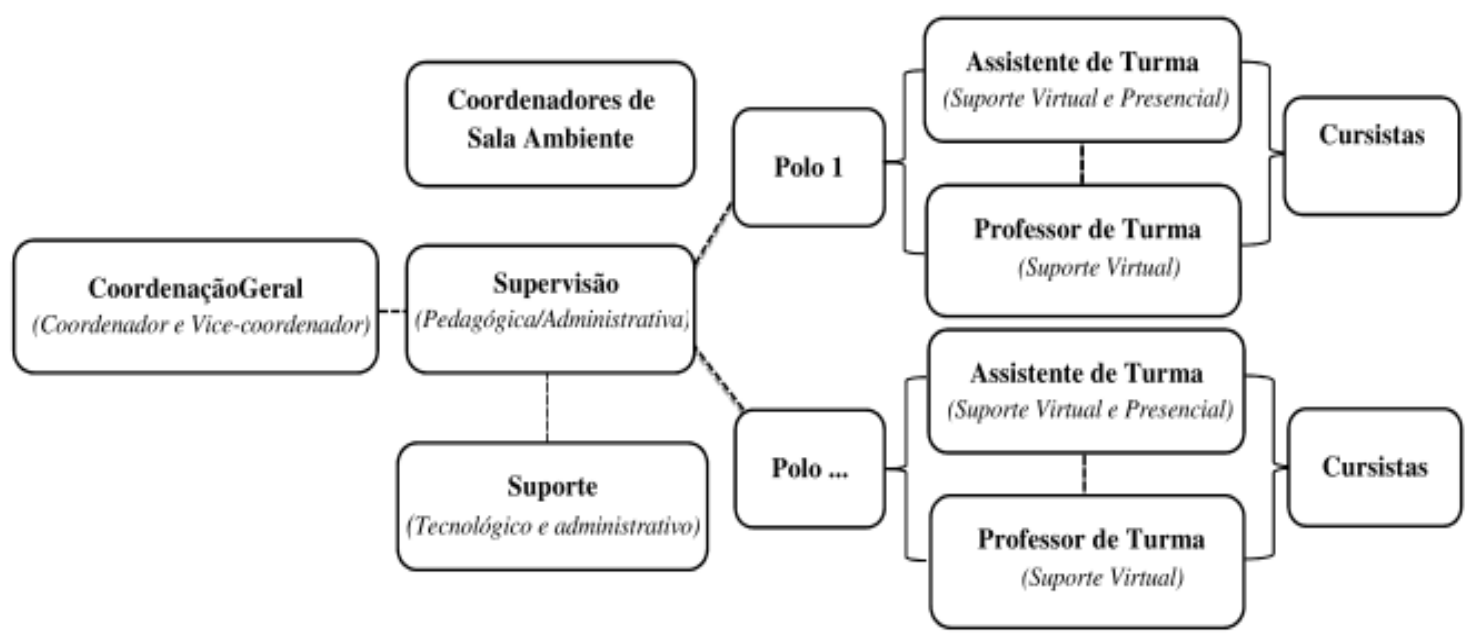

Fonte: Elaboração própria.

Com essa proposta, a equipe de supervisão assume papel relevante na articulação do trabalho pedagógico, especialmente no processo de acompanhamento dos professores-formadores, a partir das diversas ações formativas do curso. Todos esses profissionais, que possuem formação e funções distintas, são diretamente responsáveis pelo processo de ensino-aprendizagem do curso.

Esse trabalho, que inclui a organização das disciplinas e conteúdos, o gerenciamento da equipe, a supervisão e a orientação virtual e presencial dos alunos, a adequação dos conteúdos ao desenho instrucional do curso, entre outros, é aqui entendido nos termos de uma polidocência proposta por Mill (2010), caracterizada pelo coletivo de profissionais que contribuem para o fazer docente na $\mathrm{EaD}$, compartilhando e distribuindo a responsabilidade pelas atividades propostas.

\section{Aspectos metodológicos}

Foram realizadas 26 entrevistas individuais em profundidade com a equipe polidocente do programa no período de 2013 a 2015: 10 professores de turma (PT), oito assistentes de turma (AT), três professores coordenadores de sala ambiente (PCSA), três supervisores pedagógicos (SP) e dois membros da equipe de suporte administrativo e tecnológico (SA/ST). As entrevistas foram realizadas a partir de um roteiro semiestruturado, elaborado com questões que contemplassem as seguintes dimensões: (i) experiência docente e trajetória profissional; (ii) percepções sobre a formação 
continuada de professores na modalidade a distância; (iii) rotinas e estratégias de formação e interação e (iv) percepções sobre o desenho institucional implementado pela UFOP.

A análise das entrevistas forneceu cinco macro categorias: (i) autonomia e concepções sobre o desenho de formação do PNEG; (ii) percepções sobre a EaD; (iii) política nacional de formação docente a distância; (iv) saberes docentes; (v) trabalho polidocente. A partir disso, cada uma dessas categorias foi analisada com a assistência do software $\mathrm{NVivo} 囚$, ferramenta que possibilita a leitura e a classificação das fontes utilizadas, a partir daquelas cinco dimensões. $O$ software permite a elaboração de análises qualitativas a partir de conceitos e classificações previamente identificados pelo pesquisador.

Em termos práticos, o NVivo® funciona como um codificador: a partir das categorias previamente elencadas, o programa realiza a codificação do material (no caso dessa pesquisa, as transcrições das entrevistas), possibilitando uma separação mais robusta dos trechos que exemplificam tais categorias, e tornando este trabalho mais ágil, em comparação com a alternativa manual. A rigor, portanto, a lógica de funcionamento do software é bastante simples e mecânica. Este procedimento de codificação é o cerne do trabalho no NVivo® e embasa todos os demais procedimentos a serem adotados, uma vez que, para que qualquer parametrização seja feita, é preciso que os dados já estejam codificados segundo as categorias.

As categorias analíticas empregadas no estudo foram operacionalizadas a partir de "nós" no software NVivo®. Os "nós" são os códigos segundo os quais o material de evidências disponíveis foi codificado. A Tabela 1 sistematiza quantitativamente os "nós" referentes à primeira categoria. Na segunda coluna, as fontes referem-se às entrevistas (em um total de 26, 23 foram utilizadas para essa categoria). Na terceira, os trechos dizem respeito aos excertos que foram codificados nas 23 entrevistas (nesse caso, 166). 71 trechos codificados fizeram referência direta (48) ou indireta (23) à Sala de Interação Virtual, revelando sua importância para a estratégia de formação, mediação e promoção da autonomia da equipe polidocente.

Tabela 1: Recorrência da categoria Autonomia, por fontes e trechos codificados 


\begin{tabular}{|c|c|c|}
\hline Categorias & Fontes codificadas & Trechos codificados \\
\hline $\begin{array}{c}\text { Autonomia e concepções sobre o desenho } \\
\text { de formaça }\end{array}$ & $\mathbf{2 3}$ & $\mathbf{1 6 6}$ \\
\hline Sala de interação Virtual & $\mathbf{2 3}$ & $\mathbf{4 8}$ \\
\hline Autoidentificação de posição & 18 & 25 \\
\hline $\begin{array}{c}\text { Comparação entre desenhos de formação de outras } \\
\text { instituições e cursos de EaD }\end{array}$ & 17 & 26 \\
\hline $\begin{array}{c}\text { Conhecimento sobre o desenho de formação do } \\
\text { PNEG-UFOP }\end{array}$ & 13 & 19 \\
\hline $\begin{array}{c}\text { Influência do desenho para a interação da equipe } \\
\text { polidocente }\end{array}$ & 9 & 11 \\
\hline $\begin{array}{c}\text { Percepç̃̃es sobre o desenho de formação no PNEG- } \\
\text { UFOP }\end{array}$ & 6 & 7 \\
\hline Autonomia & 3 & 3 \\
\hline Constrangimento e conformação institucional & 4 & 4 \\
\hline Relaç̃̃es de poder e hierarquia & 23 & 31 \\
\hline PTs-ATs de cada polo e conteudistas & 3 & 4 \\
\hline PTs-ATs de cada polo e demais profissionais & 3 & 4 \\
\hline Supervisão-coordenação e PTs-ATs & 16 & 23 \\
\hline
\end{tabular}

Fonte: Elaboração própria, a partir dos dados extraídos do NVivo.®

A análise das entrevistas associadas à Sala de Interação será realizada na próxima seção.

\section{A Sala de interação Virtual: a relação da equipe polidocente no ciberespaço}

Conforme descrito no desenho do PNEG, cabe aos professores e assistentes de turma a gestão acadêmica de seus respectivos polos, acompanhados pela equipe de supervisão. Eles medeiam os conteúdos das disciplinas, atuam no ambiente virtual dando suporte aos alunos, orientam a realização das atividades e auxiliam nas dúvidas em relação aos conteúdos disponibilizados.

Tendo em vista as experiências vivenciadas anteriormente em outros projetos na modalidade a distância e a literatura sobre a mediação pedagógica no ciberespaço (Lévy, 1999; Silva, 2012; Peters, 2003), uma das prioridades da equipe de coordenação era criar um ambiente de interação que fosse capaz de lidar com alguns dos desafios próprios da sala de aula no ciberespaço, marcada pela liquidez entre o tempo e o espaço e pela emergência de conflitos, dúvidas e ruídos próprios da micropolítica das relações ali configuradas.

Para fazer frente aos desafios da implementação de modo a conjugar a virtualidade do curso à proximidade (e algumas vezes, à presencialidade) necessária à 
EaD, a Sala de Interação Pedagógica foi criada dentro da plataforma Moodle. A Sala é um ambiente que pretende promover a relação entre supervisão, coordenação e equipe pedagógica; fortalecer os vínculos próprios da polidocência; disseminar as informações associadas às rotinas e processos; alinhar as expectativas, tensões, ações e estratégias; criar oportunidades de trocas e apoios relacionais; compartilhar angústias, experiências e soluções; fomentar a circulação dos saberes entre a equipe e estimular a autonomia.

Nesta Sala, todos os formadores estão inscritos, sem divisões. Além de terem acesso aos documentos e tutoriais do curso, são propostos fóruns de interação e de discussão sobre temáticas relacionadas ao cotidiano das escolas e da gestão escolar. A equipe pode dialogar entre si, trocar impressões sobre suas turmas e acrescentar tópicos de discussão, através de recursos de comunicação síncrona e assíncrona. ${ }^{7} \mathrm{Na}$ sala ainda são apresentadas sugestões de leitura, dicas de vídeos, filmes e eventos acadêmicos e culturais, horizontalizando os espaços. Não há obrigatoriedade de participação, mas a experiência revela que a maioria dos formadores tem aderido e a presença deles é constante, apesar de a intensidade das postagens ser desigual entre os participantes.

\section{Percepções sobre a Sala}

Segundo Campos e Martins (2014), um dos principais desafios de um curso a distância consiste em assegurar a qualidade nos processos de mediação e interação. Nesse sentido, a primeira questão que se coloca é a superação da distância espacial e temporal existente entre os participantes do ambiente virtual de aprendizagem (AVA). A primeira distância a ser superada é a existente entre a própria equipe de mediadores. Assim como os alunos, os professores e assistentes de turma também se encontram distantes fisicamente uns dos outros e estão, de certa forma, separados no ambiente virtual.

É por isso que, de acordo com Kensky (2007), é fundamental que se sintam próximos, em conexão, independentemente do lugar em que estejam. As entrevistas revelam que os formadores reconhecem a importância da Sala, realçando seu papel para o atingimento desses objetivos.

\footnotetext{
${ }^{7}$ Entre os recursos mais utilizados na Sala de Interação Pedagógica, destacam-se os vídeos, os áudios em
} formato mp3, os fóruns de discussão, fóruns de notícia, os chats e a caixa de mensagens. 
As assistentes de turma às vezes ficam um pouco desamparadas, talvez pela distância. A Sala ajuda porque diminui a carência. O professor da EaD é um pouco carente (SP1).

É um dos motivos da Sala: promover diálogo. É errado a EaD ter que ser diferente da educação presencial. Isso enfraquece o diálogo que tem que existir (ST).

Sou grata a UFOP por ter tido minha parceira como PT. Fomos muito companheiras uma da outra (AT1).

\section{A Sala de Interação como espaço de implementação da formação}

Em relação ao PNEG (não apenas a ele, mas a qualquer programa ou política), sua implementação está diretamente relacionada com a operacionalização de um conjunto de ações que envolvem diversos setores, instituições, processos e sujeitos vinculados a uma demanda, frentes de trabalho ou rotinas administrativas e pedagógicas. Nesse sentido, a implementação pode ser compreendida como o momento em que as diretrizes definidas pela Universidade e pelas equipes de coordenação e supervisão pedagógica são efetivamente colocadas em prática, dando sentido, concretude e visibilidade ao que foi desenhado a priori.

Ball (2012) afirma que é na implementação que as tensões entre aquilo que se espera - as intenções e os resultados pretendidos - e o que de fato se obtém - os resultados efetivamente alcançados emergem. Entre esses dois extremos há um conjunto de elementos que revelam que esse processo não é linear, hermeticamente controlado e previsível: aspectos institucionais, desenhos administrativos e organizacionais distintos; burocracias e agentes públicos com capacidades institucionais e saberes diferentes; múltiplos arranjos políticos e agendas locais e os distintos interesses, expectativas e estratégias de operacionalização que conformam o cotidiano do trabalho de uma equipe polidocente (novamente, pode-se alargar o espectro, englobando outros sujeitos envolvidos no processo de operacionalização de qualquer política ou programa).

No caso dos professores-formadores, os dados e as entrevistas revelam que tais sujeitos não residem nos mesmos territórios, não têm a mesma formação, não têm as mesmas percepções sobre a $\mathrm{EaD}$ e o trabalho realizado, tampouco têm a mesma experiência e trajetórias profissionais. Da mesma forma, não atuam nos mesmos polos e não trabalham com os mesmos cursistas. Além disso, há um conjunto de processos, 
normas, prazos e demandas que são inerentes ao trabalho cotidiano empreendido, que também precisam ser esclarecidos e compreendidos pelos formadores.

Inicialmente, para a gente que não é dessa área digital, é mais complicado. A gente não abre os negócios [referindo-se aos recursos disponibilizados na Sala de Interação], e não vê assim com tanta facilidade. É bom para chamar a atenção e puxar a orelha porque às vezes a gente se perde com as datas. É muita coisa para prestar atenção! (PT3).

No caso do PNEG na UFOP, nos diversos micro ciberespaços onde a formação acontece, demarcados pelas salas ambiente que reúnem os cursistas, formadores e equipe de supervisão dos respectivos polos, há, portanto, um distanciamento entre o contexto da prática e o oficialmente previsto, razão pela qual importa entender como os formadores interpretam o que a eles é anunciado, o que deles se espera e quais são as ressonâncias que esses processos geram. Duas professoras tratam dessa questão:

Eu me sinto autônoma, porque me é dado este espaço, mas também porque eu atuo, ajo e tomo iniciativas. Eu faço, opino, discordo, concordo... Peço perdão, mas não peço permissão. Também sou professora e sei o que preciso e quero fazer (PT2).

Muita gente enxerga a $\mathrm{EaD}$ como 'ah, é à distância, qualquer um consegue'. Tem um grau de dificuldade também, tem que vencer cada etapa, não é porque é educação à distância que pode deixar o aluno se virar para lá. A coisa não funciona dessa maneira. É por isso que acho que a Sala nos vincula como equipe (AT5).

É exatamente por isso que são diferenciadas as interpretações que professoresformadores têm em relação a tais ações. Segundo Ball (2012), a prática cotidiana dos sujeitos que atuam nos [ciber] espaços escolares influencia diretamente a compreensão do texto da política oficialmente proposta. Em outras palavras, os formadores reinterpretam, recriam e recontextualizam a política, em um processo contínuo de traduções. Nesse sentido, afirma a autora, o que esses profissionais pensam - mas também como e por que pensam - têm fortes implicações na operacionalização das políticas no nível local.

A Sala de Interação como um espaço de mobilização de saberes

As entrevistas indicam que os professores se utilizam deste ambiente para partilhar seus saberes uns com os outros através dos "macetes", dos modos de fazer e 
dos modos de organizar a rotina, além de trocarem informações sobre os alunos, dividindo, uns com os outros, um saber prático sobre sua atuação. Uma das assistentes trata dessa questão:

Eu tenho um caderninho com o nome completo e o contato de cada aluno. Foi uma dica da (...) [referindo-se a assistente de outro polo]. Ela me chamou no Skype e me contou como ela faz depois que postei na Sala de Interação minha preocupação com alguns alunos que estavam sumidos da plataforma (AT3).

Seguindo nessa direção, para que essa dinâmica aconteça, é necessário que os professores e assistentes de turma mobilizem constantemente o "estoque" de saberes que carregam ao longo de sua trajetória docente. Pimenta (2005) considera que os professores reelaboram os seus saberes em confronto com suas experiências práticas vivenciadas no cotidiano de seu trabalho, sendo que "[...] é nesse confronto e num processo coletivo de troca de experiências e práticas que os professores constituem seus saberes como praticum, ou seja, aquele que constantemente reflete na e sobre a prática" (p. 29). Uma das supervisoras, ao comentar sobre como lida com a gestão da equipe, ilustra bem essa questão:

A gente precisa ter a medida certa. Sempre que você precisar conversar virtualmente com alguém da equipe, tem que ser o mais claro, objetivo e delicado possível, especialmente quando se trata de um puxãozinho de orelha. Alguns desses princípios eu acabei aprendendo na prática, fazendo o errado ou o meio certo. Isso contribuiu muito para o meu amadurecimento virtual [grifos nossos] (SP1).

Como os professores e assistentes de turma desempenham papel estratégico na polidocência, os saberes sistematizados a partir da experiência docente são fundamentais para que o processo aconteça. Construídos e sistematizados através das certezas subjetivas acumuladas individualmente ao longo de suas carreiras, também são partilhados nas relações com outros professores. A interação com outros professores e o confronto entre os saberes produzidos pela experiência individual vis-à-vis a experiência coletiva e as certezas subjetivas se transformam num discurso da experiência capaz de informar e de formar outros docentes, fornecendo uma resposta a seus problemas. Esta é outra dimensão do saber polidocente no PNEG, conforme destacado nos excertos:

Minha experiência pode servir para outra colega. Eu acho que é mais efetivo na Sala de Interações porque é um espaço que a gente pode acessar o tempo inteiro (PT5). 
Com o passar do tempo a gente vai pegando a prática na Sala. Pude compreender melhor a parte da supervisão e dos formadores e dar a minha contribuição em termos de sugestões e melhorias. Isso para mim foi bem bacana (SP2).

A Sala de Interação também tem sido um espaço rico para subsidiar o fazer pedagógico e o processo de ensino-aprendizagem. Por causa das trocas e das relações que ali são processadas, tem se mostrado uma estratégia interativa eficaz para fomentar o trabalho colaborativo da equipe na elaboração de propostas e materiais, na discussão de procedimentos e dificuldades encontradas. Na mesma direção, tem servido para desvelar a realidade dos cursistas, suas dificuldades, dilemas, problemas e demandas, fomentando e reordenando o planejamento das estratégias de formação, na perspectiva da avaliação continuada, como pode ser identificado na transcrição:

Eu nunca trabalhei sozinha nesse curso! Como estou no polo e estou mais perto dos cursistas, sei dos problemas. Não é fácil fazer um curso EaD. E a supervisão quer me escutar, quer saber o que se passa aqui para ver como ajudar. Sempre tive apoio quando precisei (AT6).

Esta é uma dimensão importante do saber polidocente na EaD: os professores não rejeitam os outros saberes docentes, mas os incorporam à sua prática, retraduzindoos e reelaborando-os em categorias do seu próprio discurso, consolidando a cultura de formação que se tornará própria de cada instituição. Segundo Tardif (2014, p. 71), os saberes docentes são "[...] produzidos pela socialização, isto é, através do processo de imersão dos indivíduos nos diversos mundos socializados, nos quais eles constroem, em interação com os outros, sua identidade pessoal e social".

A presença das equipes de supervisão e tecnologia: a Sala como apoio institucional

Do ponto de vista institucional, a Sala de Interação assegura presença e apoio da equipe de coordenação para que a implementação das ações aconteça, evitando que os formadores se sintam sozinhos, perdidos ou desamparados na linha de frente. Como os professores e assistentes de turma são os responsáveis diretos pela mediação com os cursistas através das atividades avaliativas, dos recursos didáticos e das mídias que dão sentido ao percurso formativo em cada sala ambiente, o suporte para que os formadores se sintam apoiados é vital. Dois excertos evidenciam isso: 
A educação à distância era algo que a gente fazia sem ter muita certeza do que estava fazendo [referindo-se a sua experiência em outra instituição]. Aqui não. Há presença. Há suporte (AT7).

Antes eu ficava desconfortável com isso, agora não fico mais, já perdi a vergonha. O que eu tenho dificuldade, eu peço a ajuda do (...) [referindo-se ao responsável pelo suporte]. Ele resolve tudo. A Sala é para isso, para facilitar. Se for para dificultar, se for para constranger, não serve, então tem que ter alguma intimidade, não é? (PT6)

A imensa profusão de textos, vídeos, hipertextos e hipermídias que estão "à mão" do professor-conteudista exige que se faça uma seleção e adequação dos recursos à proposta pedagógica do curso, dialogando com a trajetória que se pretende oportunizar em cada sala. A noção de trajetória baseia-se na ideia de que a formação não tem um sentido único e está sujeita a (re)significações, constrangida pelos deslocamentos pedagógicos, pelas contingências econômicas, culturais e políticas, pelas modificações interpretativas que serão realizadas pelos cursistas e pelo imponderável inerente à dinâmica que se estabelece nas trocas e nas relações construídas em sala de aula, notadamente nas salas do ciberespaço.

Como o trabalho é realizado por uma equipe polidocente, é importante que os que estão mediando a interação e a formação com a equipe confiem e acreditem no currículo e na trajetória propostos. Como tal currículo não é uma mera transposição das estratégias adotadas na educação presencial, é preciso que a equipe de supervisão pedagógica avalie e ajuste o material e as atividades propostas pelos professores coordenadores de sala ao tempo previsto para cada disciplina (distribuindo-o em unidades ou semanas), às horas de estudo de que dispõem os cursistas (professoresgestores em exercício, muitos deles trabalhando em dois turnos) e ao próprio tempo necessário à construção/produção do conhecimento, a partir da realidade e do perfil dos discentes.

Diante da experiência acumulada com a primeira turma do PNEG, percebeu-se a importância de uma ação sistemática em torno das atividades de planejamento e implementação dos conteúdos, recursos e materiais no AVA do curso, de modo a criar uma interface mais “amigável” à navegação dos usuários. Tal importância pode ser compreendida se considerarmos os pressupostos do design instrucional que, para Filatro (2007, p.65), é a “[...] ação sistemática de ensino, que envolve o planejamento e a utilização de métodos educacionais em situações didáticas específicas, a fim de facilitar a aprendizagem a partir dos princípios de aprendizagem e instrução conhecidos”. 
Atenta ao design, esta equipe passou a sugerir o número de páginas/leituras adequado para cada unidade, além de avaliar e decidir que ferramenta (chat, fórum, envio de tarefa, wiki, etc.) melhor se ajusta à determinada proposta de atividade, preservando a coerência, o percurso e a intenção didática pretendida pelo professorconteudista. Da mesma forma, a data limite para que cada atividade fosse realizada passou a ser acompanhada pela equipe, quando o domingo passou a ser o dia-referência para todas as salas/atividades.

Focada na "usabilidade", parte da equipe polidocente desenvolveu um modelo de desenho instrucional, que passou a ser implementado a partir da segunda turma. Em linhas gerais, todas as salas ambientes passaram a seguir um "padrão estético", conferindo uma identidade visual ao curso. $\mathrm{O}$ objetivo era apresentar uma sala ambiente mais "limpa", intuitiva e amigável, com ícones e entradas específicos para cada tipo de informação, assunto e atividades. Tais ícones conduziriam intuitivamente o cursista e os formadores para páginas externas ou internas, permitindo-o navegar dentro e entre cada unidade prevista. Como a Sala de Interação também segue esse modelo, a equipe se sente apoiada para desempenhar suas funções, como se pode perceber em um dos trechos reproduzidos:

Eu me sinto confortável. A plataforma é muito clara! Mas se há alguma dúvida, é só entrar na Sala de Interação. Está tudo lá e a gente acha fácil o que precisa (AT1).

Porque tudo isso precisa ser realizado com antecedência para ser disponibilizado e replicado para os diversos polos e para os cursistas matriculados, o auxílio da equipe de coordenação, supervisão e suporte tecnológico é fundamental para o bom andamento das salas ambientes e para que o cronograma das atividades seja cumprido. Assim, a equipe realiza o planejamento com antecedência, descreve detalhadamente as informações, testa os links, verifica as configurações de data/hora, monitora o funcionamento do AVA junto aos setores de tecnologia, e cuida para que o desenho de cada sala seja coerente, agradável e intuitivo, dando ao cursista e aos formadores condições de seguir adiante. Uma das professoras entrevistadas trata dessa questão sob o ponto de vista do suporte:

$\mathrm{Na} \mathrm{EaD}$, eu me acho parte de uma equipe maior, eu não preciso produzir o conteúdo que outra pessoa produz. Não preciso me preocupar com edições, com links. Como tem a equipe por trás, posso 
me concentrar no meu trabalho com os alunos. Esse é um suporte importante da equipe e da Sala (PT7).

\section{Considerações finais}

Na medida em que os sujeitos e as instituições se tornam mais porosos às TDICs em função das pressões e possibilidades advindas da sociedade em rede, da liquidez do ciberespaço e da cibercultura, o processo de mediação pedagógica torna-se mais complexo, sugerindo que as estratégias pedagógicas devem ser repensadas a fim de contemplar as transformações proporcionadas pelas tecnologias.

A virtualidade da interação, as questões institucionais e a interação cotidiana que definem os processos pedagógicos e administrativos no PNEG na UFOP potencializam a emergência de contradições, dificuldades e desafios. As distintas traduções e ressignificações que advém do processamento das rotinas e da ativação dos saberes que fazem parte da trajetória docente de cada formador conformam, então, uma micropolítica no ciberespaço, onde todos esses atores atuam, se encontram e estabelecem, em maior ou menor grau, relações formais e informais de proximidade.

É preciso, então, assimilar as condições em que o trabalho polidocente é realizado na prática e criar estratégias para que a interação aconteça e que o trabalho seja mais cooperativo e orgânico. Dessa forma, os saberes acumulados circularão e serão capazes de produzir outros, articulados e convergentes com os objetivos que se pretendem alcançar, a partir do desenho institucional.

Essa é a principal contribuição da Sala de Interação Virtual no PNEG. Ao se configurar com uma arena virtual - um hub onde a comunicação multimodal entre a equipe é oportunizada, as entrevistas realizadas revelam que esse ambiente tem contribuído decisivamente para a conformação de uma cultura de formação polidocente nesse projeto, na Universidade Federal de Ouro Preto.

\section{REFERÊNCIAS}

BALL, S. et al. How schools do policy: policy enactments in secondary schools. London: Routledge; New York: Taylor \& Francis Group, 2012.

BELLONI, M. L. Educação a distância. $6^{a}$ ed. Campinas, SP: Autores Associados, 2012.

BAUMAN, Z. Modernidade líquida. São Paulo: Editora Zahar, 2001. 
CASTELLS, M. A Sociedade em Rede. A era da informação: economia, sociedade e cultura, v. 3. São Paulo: Paz e Terra, 2000.

FILATRO, A. Design instrucional contextualizado: educação e tecnologia. São Paulo: SENAC, 2007.

GATTI, B. A. Análise das políticas públicas para formação continuada no Brasil, na última década. Revista Brasileira de Educação. v. 13, n. 37, jan./abr. 2008.

KENSKY, V. M. Educação e tecnologias: o novo ritmo da informação. Campinas: SP.

LÉVY, P. Cibercultura. São Paulo: Editora 34, 2009.

LÉVY, P. 1999. A inteligência coletiva: por uma antropologia do ciberespaço. 2. ed. São Paulo: Loyola.

MILL, D. R. S. RIBEIRO, L. R. C; OLIVEIRA, M. R.G. (Orgs.). Polidocência na educação a distância: múltiplos enfoques. São Carlos: EdUFSCar, 2010.

MORAN, J. M. A educação que desejamos: novos desafios e como chegar lá. 2. ed. Campinas, SP: Papirus, 2007.

PETERS, O. A Educação a Distância em transição. São Leopoldo, Editora Unisinos, 2003.

PIMENTA, Garrido Selma. Saberes pedagógicos e atividade docente. $4^{\circ}$ ed. São Paulo: Cortez, 2005.

SILVA, M. Educação on line. São Paulo: Edições Loyola, 2012.

TARDIF, M. Saberes docentes e formação profissional. $17^{\circ}$ ed. Petrópolis, RJ: Vozes, 2014.

\section{Como referenciar este artigo}

OLIVEIRA, Breynner Ricardo de.; MARTINS, Lídia G.; DUARTE, Adriana Otoni S. Interação no ciberespaço e formação de professores: análise da sala de interação virtual do programa escola de gestores na Universidade Federal de Ouro Preto. Revista IberoAmericana de Estudos em Educação, Araraquara, v. 12, n. esp. 2, p. 1441-1461, ago./2017. Disponível em: <http://dx.doi.org/10.21723/riaee.v12.n.esp.2.10078>. EISSN: 1982-5587.

Submetido em: 08/07/2017

Aprovação final em: 20/08/2017 